\title{
Large lakes and their sustainable development
}

\author{
edited by Max M. Tilzer ${ }^{1}$ and Peter Bossard ${ }^{2}$ \\ 1 Limnological Institute, University of Konstanz, Mainaustrasse 212, D-7750 Konstanz, Germany \\ 2 Lake Research Laboratory EAWAG/ETH, CH-6047 Kastanienbaum, Switzerland
}

Key words: Large lakes; ecophysics; biogeochemistry; food webs; ecology; research priorities.

\begin{abstract}
This contribution has been edited from a working document, prepared by invited scientists attending a workshop in Konstanz, Germany, on the importance of external perturbations for short- and long-term changes in large lakes ecosystems, held from 21 to 26 October, 1991. It tries to assess our current understanding of the most important processes involved in the functioning of large lakes and to identify the currently most urgent research priorities in the fields of land-water interactions, physical processes, biogeochemistry and nutrient relations, remote sensing, biological interactions in food webs, and long-term monitoring programs.
\end{abstract}

\section{Introduction}

Large lakes world-wide are experiencing environmental stress, and the proper functioning of many of their important ecosystems is in danger. Under current pressure no one can predict how long they will be able to serve as renewable sources of pure surface fresh water for domestic, industrial and agricultural uses, or as sources of protein-rich food.

The total area of lakes on earth amounts to approximately $2.5 \cdot 10^{6} \mathrm{~km}^{2}$ or $1.8 \%$ of the continental area, containing $1.2 \cdot 10^{5} \mathrm{~km}^{3}$ of water. The 253 largest lakes (larger than $500 \mathrm{~km}^{2}$ ) of the planet contain an estimated $78 \%$ of the world's unfrozen surface fresh water and thus represent an essential global life support system.

In many regions, large lake ecosystems have already degraded and can be returned to desirable water quality only by enormous effort and at great cost. Analysis of this negative experience from a diversity of large lakes could help governments and politicians of all nations to better allocate their resources for management and conservation of water resources. Control of human activities on the catchments may require special governmental interventions such as the establishment of regional planning agencies and other institutional arrangements among countries. Regional planning and management of entire catchments are essential to prevent degradation of water quality and to avoid huge expenditures for remedial measures. This is in accordance with the goal of sustainable development. 
The main objective of this workshop on the importance of external perturbations for short- and long-term changes in large lakes was to assess our current understanding of the most important processes involved in the functioning in large lake ecosystems, and thereafter to identify the currently most urgent research priorities. The workshop was sponsored by UNESCO under the auspices of the Man and Biosphere Program (MAB) and by the Deutsche Forschungsgemeinschaft.

\section{Distinction between large and small lakes}

Three main criteria can be used to distinguish large from small lakes: (1) Only large lakes have a true pelagial zone that is physically distinct from the littoral zone. (2) The mixing depth of the epilimnion which is a function of mean wind velocity and frequency, and of wind fetch, in general is greater than in small lakes. (3) Only in large lakes can differences in physical forcing over the water surface allow the formation of areas whose physical structure differs from other areas of the lakes. Physically different structures can cause horizontal differentiation of biological processes, generally known as patchiness.

Large lakes on average are deeper and have in general smaller watersheds in proportion to their volumes than small lakes. As a consequence, large lakes have longer water retention times than small lakes. Many receive proportionately less sediment and/or nutrient inputs and, consequently, are clearer and more oligotrophic than small lakes.

The morphological features of large lakes strongly affect the biogeochemical cycles within the water body. The area to volume ratio, and hence the interaction between the pelagial and the benthic zone, is less in large than in small lakes. The free-water zone is the main site for the bulk of metabolic processes which drive the biogeochemical cycles. In a system that has a long water retention time, any substance entering the lake will remain there for long periods of time. Thus, larger lakes are expected to respond more slowly to external inflow, but also should have longer recovery times to external influxes of any undesirable substances. The time elapsing before a particle reaches the lake bottom is longer in a deep lake, thus providing more opportunity for chemical interaction with the surrounding water.

During the growing season nutrient regeneration is more intense in oligotrophic than in eutrophic systems. Because large lakes in general are more oligotrophic than smaller lakes, regenerated production usually comprises a greater proportion of total production than in small lakes. Furthermore the food web structure tends to be controlled by bottom-up rather than top-down mechanisms, although in some lakes opposite observations have also been registered.

\section{Physics and biogeochemistry of large lakes}

Biogeochemical processes in lakes exist as a balance between the interactions of the lake with its catchment, the atmosphere and in-lake processes. This balance can shift dramatically with basin size, latitude and climate. Our current understanding of 
lake ecosystems is biased by our overwhelming reliance on small, mid-latitude temperate lakes, the main feature of which is their pronounced seasonality. In comparison, little information about high latitude and low latitude lake systems is available, and the processes controlling these diverse systems are poorly understood. The challenge for producing reliable predictions about the responses of these systems to environmental change requires an integrated scientific approach which addresses the wide range of diversity that large lake systems possess. Otherwise we risk encountering lake responses outside our experience and theoretical background, and we may face important environmental decisions with great uncertainty.

Large lakes integrate and respond to climate and other environmental forces on a regional scale. They are excellent sites to assess ecosystem variation at different latitudes and in different vegetational regions. Lakes respond to their environments, but they are also products of their environments. Among the physical conditions that set the constraints for lake response are latitude, topography, structure and composition of soils and bedrock, groundwater-aquifer relations, and geothermal factors. These characteristics react with climate and organisms in basin-specific fashions. For instance, basin morphometry, especially the ratio of mean depth to maximum depth can influence how changes in water balance of a lake become expressed as changes in lake level. Surface fetch, orientation to the wind, and littoral interactions have profound effects on mixing and circulation patterns, as well as on erosion and sediment transport. The ratio of drainage basin area to lake surface area and to lake volume interact with water budgets in fundamental ways. The magnitudes and classes of lake responses differ according to durations and magnitudes of perturbation events. There are also important time scale effects which influence the expression of a signal of environmental change.

\section{Biological interactions in large lakes}

Large lakes are important natural resources. Understanding the components of the food webs comprising these lakes is essential for their protection and improved management. Many of these lakes contain large numbers of endemic species and contribute to global biodiversity. Although the biological components of any ecosystem can be characterized by simplistic descriptions (e.g., taxonomic lists, diversity indices, etc.), such components are best described by the complex interactions among organisms. These interactions determine the structure of the food web, how efficiently it works, and how it responds to external and internal perturbations. Food web dynamics are highly sensitive to physical and chemical processes and moreover are indicators for stresses resulting from a variety of human activities. Knowledge of these interactions is important for the improved understanding of factors affecting water quality, food production, and other economic and social values.

\section{Scientific scope of suggested projects}

Projects should be designed to further our understanding of mechanisms which govern the functioning of large lake ecosystems and to allow their continued use as renewable resources of fresh water and food for present and future generations. 
Comparative and integrative studies are proposed for large lakes under different climatic, physical, chemical, and biological constraints. In addition to developing indepth scientific understanding of large lake systems in their natural state, it is important to model and predict the behavior of these systems under anthropogenic pressure. Understanding these systems is a prerequisite for effective management of essential and irreplaceable water resources. Appropriate modelling can support cost effective management strategies.

The scope of a large lakes international program should encompass five basic questions:

1) What is the current environmental status of the large lakes in the world?

2) How are these lakes changing?

3) How are external forces (e.g., climatic variability, nutrient loading, contaminant inputs, introduction of exotic species, etc.) driving these internal changes? How does lake size and location affect its response to such external influences?

4) How do the internal physical, chemical, and biological dynamics of a lake operate to affect changes in lake ecosystem structure and function?

5) What are the essential elements of a comprehensive environmental plan designed for the improved protection and sustainable development of large lakes?

We propose that actions be taken to increase our scientific understanding of the way in which large lakes function, to identify how they respond to perturbations resulting from wide-ranging human activities, and to identify those components of the lake ecosystem which are most sensitive to such perturbations. Essential to this process is the establishment of a world-wide forum for the comparison of large lakes and their problems, as well as the growth of research teams and facilities to investigate these lakes.

As a first step, the present state of knowledge about large lakes of the world should be assessed. Experts ought to collectively assemble information about individual lakes including recently observed changes in lake structure and function. Plans to develop a strategy for further comparative and cooperative studies on the large lakes could then proceed. Such an exchange of information might be conducted under the auspices of a prominent international scientific society, e.g. the 1992 SIL meeting in Spain, or the 1993 ASLO meeting in Canada.

\section{Projects}

In this section, we identify key areas of research needed to reduce risks and uncertainties stemming from the present state of our understanding of large lakes, such as land-water interactions, physical processes, biogeochemistry and nutrient relations, remote sensing, biological interactions in food webs, and long-term monitoring programs. Objectives of future research considered to be of particular importance are suggested at the end of each chapter.

\section{Land-water interactions}

Lakes in general depend on water balances maintained by hydrological inputs from their drainage basins, direct precipitation on surface waters, and losses through 
evaporation and outflow. The properties of lakes cannot be fully understood without consideration of their catchment basins. The expected consequences of forthcoming global changes in human population and climate have intensified the need for accurate hydrological models owing to increasing demand for fresh water for drinking and agriculture. Not only water quantity, but also levels of lakes and connecting waters, together with their impacts on shoreline erosion and navigation must be predicted and modelled.

Drainage basins furnish particulate matter which affects the geochemical characteristics of lakes and contributes to the transport, transformation, and removal of constituents from water. In large lakes of industrialized regions, agriculture and urbanization have sometimes resulted in eutrophication and contamination of fish and water. Understanding the models of transfer of anthropogenic contaminants is important for sustainable development of catchment basins as well as for the assessment of chemical inputs to the lake.

One important prerequisite for lake management and conservation is the development of accurate mass balances for important elements. Atmospheric transport constitutes a major pathway for tracers, nutrients and contaminants, especially in large lakes. Some mass balance models have been calibrated using anthropogenic radionuclides whose inputs are known by measurement of integrated deposition on the landscape. In order to do so, it is important to establish atmospheric monitoring and sampling sites within drainage basins. International collaboration is often essential to study and manage these systems successfully, because the drainage basins of many large lakes overlap national boundaries.

Objectives:

(1) Initiate continuous measurements and develop models of lake hydrology, lake levels, and water supplies.

(2) Characterize the composition and distribution of dissolved and suspended material in the principal tributary rivers.

(3) Establish sites for monitoring meteorological conditions of large lakes and their catchments, and for sampling atmospherically delivered material.

\section{Physical processes}

The hydrodynamics of large deep lakes, and especially the renewal of deep waters, is important, because it drives the biological productivity through replenishment of nutrients in surface waters, and because it modulates the responses of the lake ecosystem to anthropogenic and climatic influences.

In large, deep temperate freshwater lakes the vertical stability of the deep water column is orders of magnitude smaller than in tropical lakes or in the oceans. Moreover the temperature of maximum density and the pressure dependence severely constrain deep water renewal during spring and fall. Large portions of the water in deep lakes are not directly affected by wind-mixing, and are virtually independent of processes in the littoral zone.

Important questions concerning deep water renewal and vertical exchange processes remain unsolved. What role do wind-driven mixing and convergences play 
as mechanisms of deep water renewal? What is the role in mixing of thermal bars created by horizontal inhomogeneities and Coriolis forces? Are edge effects such as friction with the bottom or breaking internal waves important to the deep water renewal process, and how do such effects depend on the horizontal and vertical scales of the basin? What are the integrated rates of deep water renewal and how do they vary from year to year and in response to climate change? Do variations in concentrations of dissolved and particulate matter influence vertical mixing processes through their effects on water density?

Solution of these important problems requires the use of direct physical observations and time-dependent chemical tracer methods. High resolution hydrographic observation of temperature, oxygen, and nutrient distributions, together with current measurements, are necessary to determine physical structure and dynamics. Time-dependent chemical tracers offer the best promise for determining the integrated rate of deep water renewal. By time-series observations of chemical tracers, temperature, and external influences, the variability of this renewal can be assessed over time. This work must proceed in combination with the development of physical and empirical models of vertical mixing processes. Comparative studies of lakes which differ with respect to size and external constraints, can help us to quantify the roles of the dominant mixing processes as well as their rates.

Objectives:

(1) Develop the data base needed to quickly identify modern changes and to allow the interpretation of paleolimnological information.

(2) Measure annual thermal dynamics of lakes, together with their effects on the circulation of water, including advective and diffusive processes.

(3) Develop hydrodynamic models for lakes which differ in latitude, size, and morphometry.

(4) Initiate comparative studies of large lakes that include the mechanisms and the dynamics of deep water renewal, in order to understand the processes responsible for vertical exchange and biogeochemical fluxes.

\section{Biogeochemistry and nutrient relations}

Large lakes are well suited for the study of the responses of aquatic ecosystems to internal perturbations, which may be either physical, chemical, or biological in nature. Biogeochemistry deals with the transports and transformations of chemicals or elements from their arrival in the ecosystem, to their ultimate export, burial, or gaseous release. Basic observational data on biogeochemical fluxes are rarely available for continuous annual cycles, although it is realized that these fluxes constrain the magnitudes of ecosystem productivity. As a result, comparisons among lakes at continental scales or along latitudinal gradients are impeded by the lack of comparable data bases that would allow the identification of natural variations and the separation from anthropogenic effects.

Basic physical characteristics of lakes and their catchments help to determine water retention times, which may vary among water masses, and to infer whether or not the dominant chemical inputs to a lake are via chemical weathering and runoff, or via direct atmospheric input. Fluxes of trace chemicals and key nutrients are under 
biological control to varying degrees between lakes, depending on latitude, topography, geology, and climate. Fluxes under tight biological control are susceptible to changes in food web structure. Possibly internal physical processes (e.g., seasonal mixing) dominate the observed lake water chemistry of large, high-latitude lakes, whereas lake chemistry is increasingly controlled by biotic communities as latitude decreases.

Large lakes integrate and respond to environmental forces on a regional scale. In order to develop a comprehensive understanding of freshwater ecosystem processes, it is essential to conduct sustained observational programs of general, integrative lake properties which can be related to external forcing events. Some of the key processes requiring attention are those controlling primary biological production, vertical transport of nutrient elements, and flux rates at benthic-pelagic and littoralpelagic interfaces.

Many chemical species can be attached to particles and thereafter can be transported by advection within and between lake basins. During transport, particles undergo change or diagenesis with the release of chemicals back into the water. Ultimately the particles enter the benthic boundary layer where they either become incorporated in the bottom sediments or remain suspended. Once deposited in the sediments, post-depositional migration may occur as a result of bioturbation, diagenetic release, advection, or even molecular diffusion. These diagenetic processes are often mediated by bacteria.

For chemicals which become attached to particles, the strength of attachment is dependent on physical properties of the substance, the particles, and the water. Great variation thus exists in the transport, redistribution and fate of reactive chemicals entering a lake system.

Significant differences in biogeochemical properties may be expected in large lakes situated in different latitude ranges and in lakes of differing morphology. Equatorial lakes having permanent or semipermanent pycnoclines may become dominated by new inputs, diffusion across chemoclines, and by high concentrations of dissolved organic carbon. Shallower temperate lakes that undergo annual holomixis may be dominated by interactions with the sediments whereas very deep lakes that mix infrequently may mimic the ocean.

In order to achieve our scientific objectives, we recommend approaches that provide automated acquisition of data fundamental to ecosystem processes, over entire annual cycles. Against a foundation of standardized sampling and measurement for the most fundamental and long-term observations, we propose processoriented experimental investigations. An automated observational program should include weather stations, thermistor moorings, sequencing sediment traps, and vector-measuring current meters. These instruments will provide measurements of advective fluxes and mixing patterns which transport nutrients to the productive upper layers. The observations must be complemented with process-oriented studies of dissolved nutrients, plankton chemical stoichiometries, and physiological ecology. Both nutrient ratios and the fractionation of stable isotopes with food web transfer offer considerable promise.

In combination, these biogeochemical and nutrient studies will elucidate the major sources, sinks, and pool sizes for biologically important elements. The resulting 
modern time-series data can also be used to calibrate the stratigraphic record of surface sediments, and to forge a link to paleolimnological studies.

Objectives:

(1) Evaluate the biogeochemical cycles of nutrients for biological production.

(2) Determine the role of biotic composition in controlling the quantity and elemental composition of material exported from the trophogenic zone.

(3) Construct mass balance models of biologically and geochemically important constituents, particularly nutrients.

(4) Determine mechanisms and rates of transfer of nutrients, tracers and other constituents between water and biotic and abiotic particles.

(5) Evaluate rates of physical transport and transformation of particulate and dissolved matter in the water column.

(6) Determine the role of bottom deposits and resident organisms on mixing, burial, and exchange of constituents with overlying water.

\section{Food webs}

In temperate large lakes, two basic components of the planktonic food web prevail in oligotrophic situations: a) The "microbial" food chain from picoplankton (autoand heterotrophs) to ciliates and rotifers, and b) the "classic" food chain from nanoand microalgae to prey-grasping consumers (small herbivores) and further to predatory meso-crustaceans (carnivorous copepods and cladocerans) to exclusively pelagic zooplankton-feeding fish as top consumers. The connection between these two different transfer paths of energy is assumed to be weak in oligotrophic systems. In temperate lakes with higher nutrient levels and food concentrations, an additional third food chain from pico- and nanoplankton to filter-feeding consumers, like Daphnia, may connect the "microbial" and the "classic" food chain more closely, if filter-feeders graze on both pico- and nanoplanktic size classes. In various tertiary (old) lakes additional components have evolved which established additional pathways of energy flow, leading to more complex food webs and presumably to more effective modes for the retention of energy.

Recent studies have revealed that more than $80 \%$ of the sinking flux of particulate organic matter can be utilized by the mostly free-living bacteria, which in turn are the major food source of particle-eating metazoa and protozoa. This "microbial loop", which depends on the efficiency of liberation of dissolved organics from particulate matter, can be a major route for the flow of material and energy in pelagic food webs. There is a need to develop a mechanistic framework for bacteria - organic matter interactions, which can explain and predict specific fluxes to and from bacteria. In many respects, however, the bacteria associated with particles may be more versatile than free-living bacteria in their metabolic activities. Therefore, techniques should be developed for studying aggregates and particles in freshwater, which provide suitable microenvironments for specialized metabolic activities and may be important in the cycling of nutrients.

The microbial food web is expected to be more important for processing the primary production and cycling of nutrients in large lakes than in small lakes. The 
relative contributions of free-living bacteria, phototrophic picoplankton, metazoa and protozoa to carbon flux and nutrient dynamics is greater in oligotrophic than in eutrophic ecosystems. Because the allochthonous input of substrates is lower in large deep lakes than in small shallow lakes, the significance of pelagic microorganisms is enhanced in the former. Sampling intervals should be related to the generation time of the respective organisms. Broad seasonal studies should be complemented by intense diel studies during different seasonal phases. Bulk measurements, such as bacterial community loss rates should be specified by evaluating the properties of individual cells and populations, and by determining bactivory at the species level. Virus attack should also be taken into consideration.

Large lakes differ in the degree to which external perturbations generate changes in setting the dynamics of food webs. This is expected to be especially true for short-term meteorological events as well as regional and global climate impacts on the thermal structure. External inputs of nutrients and toxic substances are affected by land use and atmospheric fluxes. The use and cycling of nutrients and toxicants can also be determined by shifts in solar cycles and changes in ambient irradiances, especially in the ultraviolet where stratospheric ozone plays an important role.

The phytoplankton communities of various large lakes undergo fundamental changes due to alterations in mixing regimes and external nutrient loading. Phytoplankton species composition is responsive to the nutrient regime and sedimentation rates, as is the biochemical composition of the algae. These effects may propagate community-wide through trophic relationships. Proportional rates of utilization of the major nutrient elements $(\mathrm{P}, \mathrm{Si}, \mathrm{N})$ during bloom periods are expected to be useful indicators of the new production of organic matter available to secondary production.

It is presumed that modifications of the planktonic system along large-scale gradients of latitude are predomiantly characterized by controlling physical factors. In lakes of comparable size and trophy, the productivity is expected to decrease from low to high latitudes, mainly because of shorter growing seasons, exhibiting larger effects in eutrophic than in oligotrophic lakes.

From the temperate region to the subtropical arid climatic zone, a gradient from freshwater lakes to salt lakes can be observed, resulting in a decreasing diversity of plankton from low to high salinity. Latitudinal gradients of physical limnological characteristics within the temperate zone, such as mixing depth, thermal regime, stability of stratification, are expected to change plankton communities. We propose to check these hypotheses on a broad variety of large lakes at different latitudes.

The size relationships between food organisms and their predators are characteristic features of any food web structure. In nutrient-poor lakes, long food chains with many steps with low transfer efficiency are dominant. As nutrient levels increase, there is a threshold concentration above which there is a change from predatory to filtering consumers. We suppose that the food web structure in large, deep lakes is simpler than in small lakes.

Changes in planktivore abundance and feeding behaviour are known to alter zooplankton community structure, total zooplankton grazing rates, the abundance and packaging (small cells versus large) of chlorophyll, and ultimately water clarity in some lakes. Such "top-down" changes in food web structure may have important 
effects on the efficiency of energy transfer through pelagic food webs and the bioaccumulation of contaminants by various components within the food web. It is disputed whether such changes in food web structure might affect water clarity in large lakes and thus the thermal heating and cooling of surface water, as well as mixing processes in the same manner as observed in small lakes. If so, top-down changes would have important consequences for human utilization of a lake's resources and for the reduction (or accentuation) of the negative effects of eutrophication. In large lakes the majority of total productivity is associated with the pelagic zone. One should investigate, how responsively zooplankton and phytoplankton communities and apparent water quality of the pelagic zones of large lakes react to changes in piscivorous and zooplanktivorous fish stocks.

Large lakes have been manipulated frequently to enhance protein production for human use. This has often resulted in species extinctions and thus loss of global biodiversity. Management of large lakes should take into consideration the need for conserving biodiversity. Species losses often are accompanied by major functional changes in food webs. Predicting the net effects of these changes is so uncertain that any introduction of species into large lakes should be considered as very risky. Because ancient large lakes have a high degree of endemism, we suppose that biological invasions of exotic species are especially detrimental to global biodiversity.

The littoral zone is the interface between the land ecotone and the pelagic zone. Of all the regions of a lake, it is the region most affected by water level fluctuations and anthropogenic pollution. Hence, increased global warming, water diversions and water pollution potentially may exert their greatest effect on the nearshore environment. Moreover, because of the shallow, responsive nature of the littoral zone, changes in nearshore and wetland areas may provide one of the first signals of the effects of climate change on a lake ecosystem. We propose to study such effects on littoral and pelagic food webs. As lake size increases, the relative importance of the littoral zone for the lake as a whole decreases thus diminishing the availability of littoral resources. Assuming that most lake organisms depend for at least a stage in their history on littoral resources, reduction in the availability of these resources may affect recruitment, population size, as well as food web structure.

\section{Objectives:}

(1) Investigate the structures of true autochthonous pelagic food webs in large lakes and their variations over short and long timescales.

(2) Study community structures including size spectra and species composition. Consider sestonic particle distribution and sedimentation properties. Apply new techniques (flow cytometry, HPLC analysis, immuno fluorescence, RNA/DNA sequencing) to characterize the major picoplankton populations.

(3) Assess biomass and production of heterotrophic bacteria, phototrophic picoplankton, and protozoa in relation to the larger phytoplankton and zooplankton. Measure the major fluxes between phytoplankton, respectively settling seston, and bacteria and determine the efficiency of carbon transfer through the microbial and the classic food web. Develop a mechanistic framework for bacteria - organic matter interactions which explains and predicts specific fluxes into and from free-living and attached bacteria. 
(4) Measure body size relationships between consumers and their prey organisms. Observe the threshold food concentrations above which new consumers appear during the season or in long-term studies. Look for organisms with unusual trophic roles (mixotrophy, symbiosis, etc.). Assess trophic interactions with consideration of the relative importance of bottom up and top-down controls in overall community dynamics.

(5) Establish inventories and biodiversity archive collections of endemic species and assess their role in nature. Monitor biodiversity and identify ecological niches occupied by introduced alien species.

(6) Identify and quantify the uses of littoral resources by pelagic components in large lakes. Evaluate the significance of long-term and short-term changes in the availability of littoral resources on food web interactions. Evaluate the importance of the littoral zone in large lakes as an interface between land and water ecotones.

\section{Remote sensing}

Remote sensing techniques are now being successfully applied in oceanography and terrestrial ecology, but have not been applied routinely to fresh waters on large scale, although many lakes and their catchments are large enough for remote sensing to provide invaluable information and a perspective unavailabe from any other type of data gathering. Remote sensing can provide data on spatial and temporal scales of patchiness, horizontal eddies, current structure, pollutant spill trajectories, meteorological patterns and river plume propagation. Thus, remote sensing, in conjunction with simultaneous ground data acquisition, is particularly suitable for the study of the impact of large scale physical processes on biological responses such as biomass accumulation.

High priority should be given to the acquisition of remote sensing data for the world's large lakes and their catchments. Particular emphasis should be given to long-term changes in landscape characteristics and catchment development. Time scales of change from seasonal to interannual are well suited to this technology.

Remote sensing can also yield synoptic data on short-term scales relevant to large lake processes. Detailed imagery by satellite of surface temperature, chlorophyll, turbidity, ice cover and surface roughness (wave height) are routinely available at intervals from daily to monthly. Aircraft based sensors can be used to extend both the frequency and resolution of these observations.

Priority of recommendation should be given to the development of routine calibrations of remote sensing data with precise positioning and navigation by means of simultaneous acquisition of ground data.

Objectives:

(1) Implement long-term remote sensing of large lakes and their ecosystems.

(2) Conduct appropriate calibration studies for the verification of remotely sensed data, and use these data to improve physical and biological models. 


\section{Long-term monitoring programs}

Responses of large lakes to external perturbations are often slow, especially in basins with long water retention times, and may require many years for detection. Lakes undergo both annual cycles and longer inter-annual non-cyclic variations. Longterm changes in lakes are evident only after observations for several years to decades. It is important to understand natural long-term cycles in order to differentiate them from changes caused by external perturbations such as accelerated climate change, impact of human population, industry, forestry, agriculture, by short-term, but often catastrophic events such as toxic spills, fires, and large scale erosion. Patterns of change may be variable among lakes, but realistic assessment of the response of large lakes to climatic change is possible only on the bases of long-term data collection and analysis. Only then can we accurately predict future conditions. Information gathered from long-term monitoring programs will be instrumental in establishing strategies for the detection and prevention of new environmental perturbations, and for providing ecologically sound lake-wide management plans for the conservations and protection of the lake ecosystems. This information will be essential to assess the feasibility of large lake environmental protection under conditions of increasing population and other development stresses, and to determine sustainable carrying capacity of the lake and its watershed.

Objectives:

(1) Assess natural long-term cycles of major physical and chemical components, with particular reference to mass balances of nutrients and pollutants.

(2) Assess long-term trends in phytoplankton, zooplankton and benthic succession, to identify shifts in species composition. This will also allow early detection of foreign species invasions and a timely assessment of their ecological impacts.

(3) Determine pathways of contaminant transfer within the food web, with special attention to biomagnification through top predators such as fishes, birds and mammals.

(4) Initiate a program of sediment trap collection, and of lake bottom sediment studies, in order to provide information on fate and storage of accumulated material, as well as to reconstruct and interpret recent lake history.

(5) Ensure easy access and exchange of both meteorological and limnological data from various monitoring programs.

\section{Concluding remarks}

The bulk of this article has been drafted by several diverse working groups as a working document for submission to UNESCO entitled: "Large lake ecosystems and sustainable development, a plan for understanding and managing the large lake ecosystems of the world." This paper does, therefore, not intend to cover thoroughly and systematically the state of the art in large lakes research. It rather reflects the results of intensive and fruitful discussions among scientists of different disciplines and countries, trying to identify important topics and problems in large lakes research from their own diverse perspectives. Since the participants of the workshop believe 
that the document should also be addressed to a larger forum of interested scientists, the editors have attempted to summarize this working document in the foregoing report. References to the vast literature have been omitted from this summary. Interested readers are invited to consult the book edited by Max Tilzer and Colette Serruya on "Large Lakes, Ecological Structure and Function" (1990, SpringerVerlag, Berlin Heidelberg) for additional background and references.

This contribution has been reviewed by Alfred M. Beeton and John T. Lehman, Ann Arbor, Marlene S. Evans, Saskatoon, and Ray F. Weiss, La Jolla.

\section{List of workshop-participants}

"Importance of external perturbations for short- and long-term changes in large lake ecosystems", held in Konstanz, Germany, 21-26 Oct. 1991 and sponsored by UNESCO under the auspices of the Man and Biosphere Program, and by the Deutsche Forschungsgemeinschaft.

The following persons participated in the sessions and contributed to the workshop document:

\section{Convenor: Max M. Tilzer, Konstanz, Germany} Participants:

Bäuerle, Erich, Ottendorf, Germany Barica, Jan, Burlington, Canada Becker, Michael, Konstanz, Germany Beeton, Alfred M., Ann Arbor, USA Berman, Tom, Tiberias, Israel Bossard, Peter, Kastanienbaum, Switzerland Eckmann, Reiner, Konstanz, Germany Edgington, David, Milwaukee, USA Evans, Marlene S., Saskatoon, Canada Fischer, Phillipp, Konstanz, Germany Fournier, Fred, Paris, France Frenzel, Peter, Marburg, Germany Gaedke, Ursula, Konstanz, Germany Gasith, Avital, Ramat-Aviv, Israel Geller, Walter, Konstanz, Germany Giovanoli, Federico, Konstanz, Germany Goldman, Charles, Davis, USA Golterman, Han, Arles, France Gophen, Moshe, Tiberias, Israel Grachev, M. A., Irkutsk, Russia Granin, N. G., Irkutsk, Russia Guede, Hans, Langernargen, Germany Guljaewa, Galina, Irkutsk, Russia Horie, Shoji, Shiga-ken, Japan Ilmberger, Johann, Heidelberg, Germany Imboden, Dieter, Duebendorf, Switzerland Jewson, David M., Derry, Northern Ireland Kilham, Susan S., Philadelphia, USA
Kleiner, Joachim, Ueberlingen, Germany Klump, Val. J., Milwaukee, USA Kozhova, Olga M., Irkutsk, Russia Lehman, John T., Ann Arbor, USA Lenhard, Angela, Konstanz, Germany Lindner, Gerhard, Weingarten, Germany Livingstone, David, Duebendorf, Switzerland Magnuson, John, Madison, USA Moeller-Sulger, Anke, Davis, USA Müller, Helga, Konstanz, Germany Naber, Gerhard, Stuttgart, Germany Nishino, Machiko, Shiga-ken, Japan Okuda, Setsuo, Okayama, Japan Ozimek, Teresa, Warszawa, Poland Pipp, Evelyne, Innsbruck, Austria Pollingher, Utsa, Haifa, Israel Pulvermüller, Agnes, Freiburg, Germany Robbins, John A., Ann Arbor, USA Roest, F. C., Wageningen, The Netherlands Schanz, Ferdinand, Kilchberg, Switzerland Schimmele, Michael, Heidelberg, Germany Simon, Meinhard, Konstanz, Germany Stabel, Hanns-Henning, Ueberlingen, Germany Wang, Ning, Konstanz, Germany Weiss, Ray F., La Jolla, USA Weisse, Thomas, Konstanz, Germany Wessels, Martin, Konstanz, Germany 